\title{
IN SEARCH OF SUSTAINABLE BUSINESS MODELS FOR COGNITIVE RADIO EVOLUTION
}

\author{
Vladislav V. Fomin'1, Artūras Medeišis ${ }^{2}$, Daiva Vitkutè-Adžgauskienè ${ }^{3}$
}

\author{
${ }^{1}$ Turiba School of Business Administration, Graudu 68, Riga, Latvia \\ ${ }^{2}$ Vilnius Gediminas Technical University, Naugarduko g. 41, LT-03227 Vilnius, Lithuania \\ ${ }^{3}$ Vytautas Magnus University, Vileikos g. 8, LT-44404 Kaunas, Lithuania

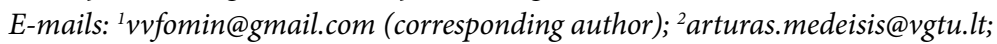 \\ ${ }^{3}$ d.vitkute-adzgauskiene@if.vdu.lt
}

Received 01 February 2011; accepted 29 June 2011

\begin{abstract}
In this paper we examine the emerging industry of Cognitive Radio/Software Defined Radio (CR/SDR), a sector which in some ways seconds the industry structure of the cellular mobile communications, while bearing distinctive characteristics. Any radio telecommunications infrastructure depends on scarce resources - radio frequency spectrum - that require policy decisions for allocation to specific countries and services. CR/SDR may constitute a new paradigm in radio communications as it may completely or partially eliminate the role of the regulator in minutiae of spectrum access authorization.

In this paper, we review scarce literature on CR/SDR to analyze the relationships between political, technological and economic factors in order to identify drivers and barriers to the emergence of new techno-economic paradigm of CR/SDR. Our discussion of business opportunities for CR/SDR includes analysis of applicable spectrum access policies and identification of those of them, which would be most fertile for the development of future CR/SDR business.
\end{abstract}

Keywords: Cognitive Radio, Software Defined Radio, wireless communications, radio spectrum access, ICT development.

Reference to this paper should be made as follows: Fomin, V. V.; Medeišis, A.; Vitkutè-Adžgauskienė, D. 2012. In search of sustainable business models for cognitive radio evolution, Technological and Economic Development of Economy 18(2): 230-247.

JEL Classification: L15, L16, L51, L53, L86, L96, O33. 


\section{Introduction}

Information and communication technologies have been among the fastest growing and innovating technologies in both production and use during the four past decades, and the prospects for future growth appear equally bright. Since the end of 1970s, the development of one particular domain of radio communication systems - that of cellular mobile telephony in Europe, the U.S., and Japan has followed divergent paths for four decades, while finally showing the signs of convergence on a single LTE standard (Stewart, Wang 2010). Divergence of technological trajectories and patterns of use have been shaped by many factors, including government regulation (West 2000), market structure (Lera 2000), and socio-cultural settings, in which technologies developed (Fomin, Lyytinen 2000). Re-convergence seems to be driven by globalization of policy, standardization and economies of scale (Stewart, Wang 2010). All these factors are relevant when studying Cognitive Radio as a sub-domain of radio communication systems (Kloch et al. 2009: 3), as CR/SDR emerges as a new re-convergence point for wireless communications industry (McHale 2010). Moreover, the CR/SDR could also fuel the necessary optimization of modern telecommunications networks and services, as they provide the means of automation and artificial intelligence required for such tasks (Sakalauskas, Zavadskas 2009).

For the existing radio telecommunications paradigm, regulations have been developed according to specific principles. One principle is that of technology-service-resource association. This means, that each communication system has an assigned (often exclusively) frequency band, and each wireless device "must have one RF module (and related antennas) for each wireless communication system being supported like GSM/UMTS, RFID, GPS, DVB-H or FM-radios" (Kloch et al. 2009: 4). Besides bearing certain implications for the design of radio communication devices (hardware and software), the current paradigm allows for interference monitoring by regulators and for assuring certain Quality of Service (QoS) by service providers. One of the major downsides of the current paradigm is that the strict frequency assignment along with the associated rigid administrative frequency allocation process often results in inefficient use of this critical resource that is equally important to service provisioning of existing systems and the appearance of innovative designs and applications (see Fig.).

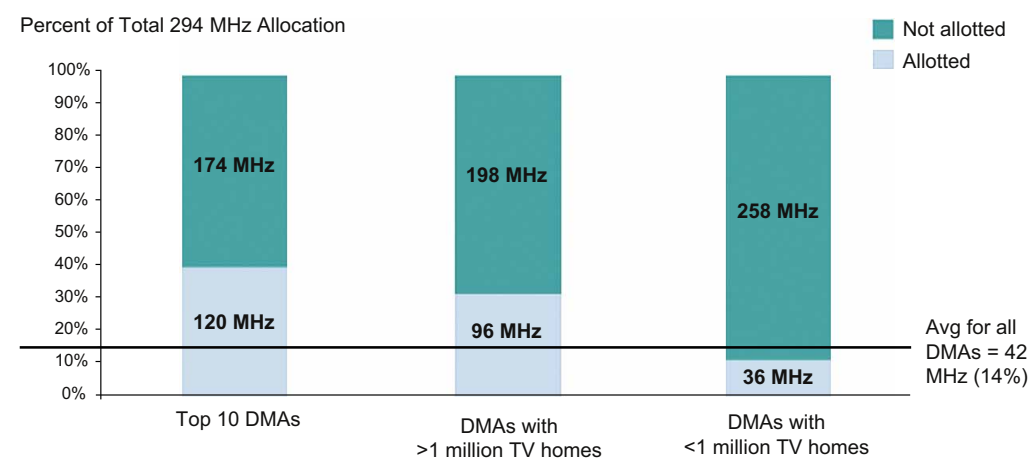

Fig. Allotment of full-power stations in the broadcast TV bands. Source: Federal Communications Commission 2010: 9 
This phenomena observed in Figure led to the creation of concept of "TV-band White Spaces" (TVWS), i.e. locally available parts of spectrum between used TV channels. Recent studies on quantifying the availability of TVWS in the UK found that for any given location a minimum of 12 channels ( $96 \mathrm{MHz}$ ) was accessible to low-power cognitive devices (Nekovee 2010: 8). Studies conducted in the United States reported results in line with the UK findings (Nekovee 2010: 8 referring to Brown, Sicker 2007; Mishra, Sahai 2009). These numbers of available TV channels correspond to having in each locality a surplus of 9-10 duplex (i.e. $2 \times 5 \mathrm{MHz}$ ) UMTS $3 \mathrm{G}$ channels, which could be seen as equivalent of providing a raw spare throughput capacity on the order of $100 \mathrm{Mbps}$, assuming HSPA transmission mode and depending on link distance, modulation technology, etc.

The advent of CR technology promises optimization of the radio networks through load balancing, spectrum re-farming, and radio resource usage optimization, among others (Mueck et al. 2010: 3). More efficient use of the spectrum will be enabled by freeing service providers from the strict association of specific bands from specific radio access technologies (RATs). CR/SDR can be independent of service considerations and usual associated bands (Tardy, Grøndalen 2010: 108).

The "cognitive" capability of CR is defined through the capability of CR devices "to select among the different wireless communication systems based on available spectrum and requirements regarding mobility, quality, bandwidth and cost" (Kloch et al. 2009: 5). CR "obtains information about the spectrum usage in an area, e.g. by using sensors for detecting radio activity, and then adapts its transmissions to both satisfy its own communication needs as well as ensuring that other radios or radio systems are not disturbed" (Tardy, Grøndalen 2010: 105). This concept was however lately complemented by the additional required features, such as reference geolocation database (GDB) that stores information on active users of the bands and their respective spectrum access rights. Such database would aid the environment classification in cases when sensing feature alone could not reliably detect the victim stations. Yet the full viability of this technique still requires further studies, as local research shows that there may be many problems encountered in individual countries when setting up and maintaining credible GDB database reference services (Stankevičius et al. 2010).

The relationship between CR and SDR is defined by the mutually beneficial symbiosis. The SDR is essentially a radio transceiver that can accommodate a significant range of RF bands and air interface modes (such as RF channel selection and waveform generation) through software (Mitola 2000). Thus SDR provides the software (SW) enabled re-configurable platform and the reduction in the physical footprint, while Cognitive Radio (CR) enables user-independent intelligence (Kloch et al. 2009: 5).

The concept of SDR has been discussed since mid 80-ties with the first commercial products arriving to the market in the early 90-ties (Kloch et al. 2009: 3). However, until now SDR has remained largely a concept, implemented in high-end applications such as military communications, multi-standard base stations of public cellular systems, etc, but failing to scale to mass market user devices. Given the fact that CR/SDR is a technology that is still very immature, the extant research has primarily focused on its technical and technological feasibility. In this paper we review the scarce literature to identify other than technology factors affecting the development of the technology. We set the scope of the in- 
quiry to match earlier studies (OECD 1999; Fomin 2001b) on complex innovation systems, which identified four interrelated domains driving market development: 1) globalization; 2) deregulation; 3) changing patterns of demand; and 4) advances in scientific and technological development.

\section{The current techno-economic paradigm of mobile communications services in Europe}

Since the 1984 European Council's (EC) Recommendation 84/549/EC, to "stop the fragmentation of the European market, to help users to have cheap prices, and to help the European industry to have a wide market" and 1987 and 1990 EC's Green Paper outlining a common approach in the field of tele- and satellite communications, a European ICT market has been oriented towards common standards and user services (Paetsch 1993: 257; Fomin 2001a: 58). This paved the way for success of such European wireless technologies as GSM.

The forerunner of European telecommunications' reform was Great Britain. In less than five years, from 1980 through 1984, the British government under Margaret Thatcher enacted the most radical pro-competitive reform of telecommunications anywhere in the world. The government separated the postal and telecommunications sides of the incumbent PTT; privatized the telecommunications side; and introduced competition in telecommunications equipment, value-added services, mobile communications, and long-distance and local telephone service. It combined liberalization with institutional reform, creating a new independent regulatory authority with a mandate to use regulation to promote competition (Fomin 2001a: 59).

The case of GSM is likely to be the most often quoted success story of the European telecommunications policy and market developments. The market regulation may confidently be called one of success factors for GSM, because a special policy developed at that time forced EU countries to allow GSM handsets to be used freely, despite these countries' own regulations ${ }^{1}$. Another important success factor for GSM was that of industry collaboration (self-regulation) through the premises of GSM MoU - the creation of uniform pan-European (and later world-wide) roaming arrangements ${ }^{2}$. The advent of GSM brought about a paradigmatic change to the telecommunications domain, helping it grow from national systems to become truly global in manufacturing, operation, and regulation. The GSM was followed by similarly well "orchestrated" pan-European introduction of UMTS systems at the turn of $21^{\text {st }}$ century, which allowed preserving a harmonized mobile telecommunications market in Europe.

Ever since the dawn of deregulation of the European telecommunications market, politicians argue for more competition and better telecommunication services for the public (Tardy, Grøndalen 2010: 105). Users seek lower prices of and wider accessibility to broadband

In Greece for example, radio receivers and transmitters were strictly controlled as a potential threat to national security. As a member of the EU however, Greece had to comply with the directive, and the use of cellular telephones became possible.

2 The roaming feature was brought to GSM by the Nordic countries, which have had this feature in their $1^{\text {st }}$ generation mobile telephony system (NMT) since the early 1980 s. 
access, while operators seek to satisfy the growing demand for mobile broadband while striving to overcome capacity limitations due to lack of the "digital dividend" - the radio spectrum (Tardy, Grøndalen 2010: 105). At the same time, measurements have repeatedly shown that at any location at any time a large portion of the spectrum is actually not used (Tardy, Grøndalen 2010: 105).

According to recent consumer survey (European Commission 2009a: 44), the biggest thing that keeps people from using mobile broadband services is the high pricing $(42 \%)$, followed by technology implementation problems (31\%). Thus, the critical value proposition of CR to the consumer should be (lower) price and (lower) complexity, including billing complexity ${ }^{3}$, as compared to the current paradigm's services. A desirable feature is supply diversity ${ }^{4}$ (Delaere, Ballon 2008: 15).

The lessons of "cost control" strategy of $3 \mathrm{G}$ operators in Europe entering the market under strong competition from $2 \mathrm{G}$ operators/services seem to be feasible for the introduction of CR/SDR services, too. For example, when launching $3 \mathrm{G}$ services in highly saturated $2 \mathrm{G}$ UK's market, Hutchinson's ' 3 ' UMTS service was drawing customers purely on the basis of a voice package that effectively gave complete control of costs by offering a high number of inclusive minutes (Stewart et al. 2003: 32).

The cost control factor aspect is tightly related to extant operator's strong position as "holders" of sophisticated billing systems. Telcos and MNOs have installed on their networks billing systems which permit the service providers to bill per second of voice or video call, per message or per kilobyte of data, or for any other transaction. Associated with billing are the security and authentication systems that make it secure and trustworthy (Stewart et al. 2003: 33). "Rather than having just one way of billing, this sophisticated billing system allows operators to package 'service products' to bill for any unit - a piece of information, a photograph, a phone call, irrespective of any actual costs to deliver, or relative the cost of another service product" (Stewart et al. 2003: 33).

Combination of SIM identification with the power of billing systems potentially allows the use of many different wireless access systems into one bill for the end user (Stewart et al. 2003: 34), thus rendering the complexity of supplied services simple in the eyes of consumer. Should new CR-enabled services lack the billing and access simplicity of the current paradigm, adoption of services is likely to see retardation. Important in this respect is the growing popularity of simple flat rate pricing schemes among consumers, whereas user subscribes to one flat fee that has no set limits on the limits (call minutes, MBs, SMS, etc.) are set so high that the average user is not likely to exceed them. This trend of accumulating all rendered services under one flat fee may be seen as the ultimate expression of billing simplicity and should be considered preferred option for future developments of CR-based or other communication services (European Commission 2009a).

Billing complexity is considered to exist if the end user is forced to enter into a billing relationship with more than one actor, which complicates an essentially transparent service to the user and decreases user value Delaere, S.; Ballon, P. 2007. Model Implications of a Cognitive Pilot Channel as enabler of Flexible Spectrum Management, in 20th Bled eConference eMergence: Merging and Emerging Technologies, Processes, and Institutions. Bled, Slovenia.

4 Whether a user is locked into the services of one operator or has a choice between multiple operators (Ibid.). 
Recent network based measurements show that when not considering iPhone, $98 \%$ of all traffic in mobile networks originates from PC's and less than 1\% from Symbian based cell phones (European Commission 2009a: 44). This is generally supported by the intuitive notion that people use data-intensive Internet applications at home, especially in the light of the by now widely established practice of file sharing. In this context it is important to note, that the rubric of "Future Wireless Home Networks" appears to be an important other driver for CRS after the mobile telephony and mobile broadband. Not burdened by spectrum licences, home wireless networking has become in the last few years a pervasive technology (Nekovee 2010: 9). Already today more than 30 percent of Europeans who own a computer are using WiFi routers at home. In the future, the wireless traffic in home environment will grow exponentially, as The Future Wireless Home Networks will embrace not only Internet connection for computers, but also media servers (High Definition TV, video and audio), wireless cameras and game consoles wirelessly connected to the Internet and one another (Nekovee 2010: 9).

Introduction of SDR/CR into the market could become a universal panacea for all involved groups of stakeholders - the operators would achieve more efficient spectrum utilization, which would decrease the cost per delivered bit and allow reduce end-user prices for and increase access to the broadband offer. Freed up or not utilized spectrum can be used by incumbent and new service providers to offer innovative services to consumers, thus enhancing the competition (Mueck et al. 2010: 1; Tardy, Grøndalen 2010: 105). CR would fulfill the regulators' strive for technology and service neutrality in spectrum management (Tardy, Grøndalen 2010: 107). Finally, novel services enabled by CR would benefit politicians, whose agendas are governed by the rhetoric of economic growth, as services are "driving the economy" and remain the fastest growing sector of the European economy (European Commission 2009a: 41). To fulfill on expected benefits, however, further legal harmonization, technology development, and standardization is needed, as it is important to ensure that new services can be developed for Europe as a whole and globally (European Commission 2009a: 8).

\section{Looking for CR/SDR business models}

Today SDR has established itself in the U.S. as an essential technology element to defense community. However, SDR's “technological evolution and current capabilities are, in most cases, well ahead of the willingness to deploy" (McHale 2010: 5). To establish itself on the wireless market, SDR must cater for the expectations and/or requirements of different stakeholders, as outlined above. This means that CR/SDR deployment in the commercial markets need to be underpinned by a viable business model and the ability to compete with similar applications offered in other bands without cognitivity (European Commission 2009c: 20).

The complexity of finding a value proposition for CR/SDR at the backdrop of established radio communication services can be modeled based on frequency allocation/use and service deployment scenarios. Different deployment models will influence the relationships between different actors in the telecommunications ecosystem, focusing in particular on the revenue sharing (Delaere, Ballon 2008: 13). 
Currently there are three basic models for regulating spectrum: command and control, market mechanism and commons model (Marcus et al. 2005: 7). But already now it becomes transparent that the rise of CR/SDR technology with its promise of spectrum access intelligence at the device level will pave way for new spectrum access modes and its governance paradigms. One of such novel paradigms which gained most traction recently, is called opportunistic spectrum access (Huang et al. 2008) along with its associated concept of spectrum pooling (Mitola 1999).

Under the command and control model, the national regulatory authority (NRA) determines exactly how the spectrum may be used in terms of technologies and services. The NRA also decides who may use the spectrum, for how long and under what further conditions (Marcus et al. 2005: 7).

The market mechanism approach requires a clear definition of exclusive spectrum usage rights (Marcus et al. 2005: 7) to permit market-regulated spectrum usage. E.g., the primary assignment of spectrum takes the form of an auction, after which usage rights can be transferred by the mechanism of spectrum trading (Marcus et al. 2005: 7). This can be typical for markets with many micro-license holders, such as Private Mobile Radio market with many single-frequency users such as taxi companies. The tradable license could either allow or not allow change of type of use and/or conditions. In the former case, is the choice of deployed technology would be left up to the users, who should be given as much freedom as possible in making this decision, to determine what services they will offer, and on the basis of which technology. This will be a commercial decision based on market factors.

Under the commons model, there are no exclusive usage rights and multiple users share to the technically possible extent the access to a single frequency band (Marcus et al. 2005: 7). The access and use of such bands are typically speculated by some sort of a general (a.k.a. blanket) license. Apart from the license conditions, which stipulate the type of services and technologies permitted in this frequency band along with some associated "good neighborhood" rules of technical nature (such as output power restrictions, some protocol rules for collision avoidance, etc.), there are therefore no restrictions on individuals and companies (Marcus et al. 2005: 8).

Under the model of opportunistic access, the new systems would gain dynamic access to a radio spectrum band that is currently used by some licensed incumbent systems on a condition that the new systems would not interfere with the incumbent systems. The prominent example of such deployment is the case of White Spaces in TV bands.

Different spectrum control models can be matched by different CR/SDR service deployment scenarios (Nekovee 2010: 9):

- wireless distribution networks/routers for future digital homes (akin to currently popular 802.11 WiFi devices),

- licensed-exempt mobile broadband,

- last mile wireless broadband in urban environments,

- cellular communications in TVWS.

The original spectrum pooling concept foresaw that a plethora of users would concurrently compete for a pool of available frequencies, e.g. managed by the owner of the licensed spectrum. A typical example would be an etiquette-defined access to the same radio frequency 
band by police force, fire brigades as well as taxi companies (Mitola 1999). However, lately this concept became indiscernibly tied into the broader context of opportunistic spectrum access (Zhao 2007) and therefore will not be separately addressed in the following discussion.

Juxtaposing spectrum allocation and service deployment options, we may obtain the following matrix (see Table).

Table. CR/SDR deployment scenarios under different spectrum allocation/sharing scenarios

\begin{tabular}{lllll}
\hline & $\begin{array}{c}\text { Wireless } \\
\text { distribution } \\
\text { networks for } \\
\text { future digital } \\
\text { homes }\end{array}$ & $\begin{array}{c}\text { Licensed- } \\
\text { exempt mobile } \\
\text { broadband }\end{array}$ & $\begin{array}{c}\text { Last mile wireless } \\
\text { broadband } \\
\text { in urban } \\
\text { environments }\end{array}$ & $\begin{array}{c}\text { Cellular } \\
\text { communications } \\
\text { in TVWS }\end{array}$ \\
\hline $\begin{array}{l}\text { Command } \\
\text { and control }\end{array}$ & Not Appropriate & Not Appropriate & Appropriate & Appropriate \\
\hline $\begin{array}{l}\text { Market } \\
\text { mechanisms }\end{array}$ & Not Appropriate & Not Appropriate & Appropriate & Not Appropriate \\
\hline Commons & Appropriate & Most appropriate & Not Appropriate & Not Appropriate \\
\hline $\begin{array}{l}\text { Opportunistic } \\
\text { Access }\end{array}$ & Appropriate & Appropriate & Appropriate & Appropriate \\
\hline
\end{tabular}

Note that in Table the conclusions regarding the suitability of one or another spectrum allocation/licensing mechanism are offered based on licensing feasibility point of view, i.e. not taking into account whether particular scenario would be technically feasible.

It may be then concluded that some of the scenarios emerge from this analysis as being predetermined (i.e. either allowed or excluded) by the choice of spectrum access regime. At the same time, one scenario of last mile access in urban environments emerges as the clear leader in terms of its adaptability to most of the spectrum access regimes. This may be explained by the assumption that this type of use scenario would be managed by the network operator, a Telco, which ensures adaptability through the facility of centrally managed network.

On the other hand, one may conclude that the scenario of opportunistic access to spectrum appears to be the one favouring CR/SDR type of use most. This may be explained by the logic that inherent cognitive features of CR/SDR systems would provide for the adaptability of deployed radio systems, which is the prerequisite of fully exploiting the promises of opportunistic spectrum access.

Looking at this situation it may be concluded that the scenarios most suitable for the Commons and the Opportunistic Access regimes would be the most favorable. This is because:

- the commons model would be beneficial for nascent emerging High-Tech companies that are lacking resources for staging forays into the market segment of licensed bands since that usually requires significant $R \& D$ investments as well as long lead-in times due to prolonged spectrum allocation and equipment standardization processes;

- the opportunistic access model would be especially beneficial for many countries due to the historically patchy use of radio spectrum whereas large chunks of spectrum are either used by obsolete systems that are incompatible with the modern standardized 
state-of-the-art systems or are hogged by the large incumbent institutional users (military, utilities, etc.) who may not need them at all times, thus introducing an opportunity for dynamic borrowing of this spectrum.

It could be also noted that the above two models are well disposed to the overall promotion of innovative development of science and technology (wireless technologies in this case). This, in turn, facilitates the further cyclic development of the knowledge-based innovative society (Melnikas 2010), and thus builds the basis for realistic scenarios of sustainable development of national economies, infrastructure and society at large (Burinskienè 2009; Melnikas 2010).

\section{Towards the new techno-economic paradigm}

In the current paradigm of mobile communications services, wireless networks thrive on private-property rights of the service providers to radio spectrum. More than $\$ 200$ billion in fixed capital has been invested by U.S. operators placing radios (base stations and handsets) into owned spectrum; at least $\$ 200$ billion in annual gains are now received by customers (Hazlett 2010: 2).

As similar figures can be expected for the European market, it is obvious that service providers would be more than hesitant to abandon the current generation of technologies if the expected benefits of the new one are not (economically) convincing. Besides, some current paradigm's fixed radio solutions are likely to be still needed in the new SDR paradigm.

Such example as FM radio warrants a situation where many spectrum licensees would not give their licensed spectrum away, thus risking the whole idea of cognitive radio paradigm (Damljanović 2010: 7). This challenge of "spectrum hoarding" may be addressed to a certain extent by existing (albeit quite novel) regulatory mechanisms, such as the Administrative Incentive Pricing, however this mechanism does not alleviate regulators from the need of making the difficult choices, kind of active market intervention, which is cumbersome and never can be proven to be measured correctly. Therefore the CR/SDR with its regulatory flexibility and prospects of efficient market self-regulation would promise a luring prospect of an elegant solution to this challenge.

\subsection{The drivers/incentives to adopt $\mathrm{CR} / \mathrm{SDR}$}

For the manufacturers (and service providers in this context), the shift to CR/SDR would help shift innovation from hardware (HW) to software (SW) paradigm. When device and service features can be altered by SW, competition implies faster sequences of updates and improvement of operating behavior of technology. Software defined radio could improve the economic benefits for industry or the consumers by reducing the equipment implementation costs (European Commission 2009c: 21). Indeed, mobile telephony service providers have had one of their feet in this paradigm for at least since the introduction of the GSM networks. Annual or semi-annual firmware/software upgrades to network equipment (made possible by implementation of SDR-based Base Stations, some of them being able to provide the multiple RATs at the same time thanks to SDR capabilities) helps mobile operators keep up with the growing demand for spectrum-hungry services through introduction of new GSM/UMTS standards and techniques into the communication network. 
For the regulators, the promised CR/SDR paradigm would ease the growing pressure of spectrum allocation problem (due to fast growing demand for wireless data communications, for example) as well as endless dilemma of administratively choosing the most appropriate (worthy) recipient of any "new" spectrum. Therefore, centralized policy based management and control in the radio communications domain must be changed to accommodate selforganization (European Commission 2009a: 14).

For the consumers, the introduction of cognitive radio would offer improved access to a plethora of existing and future innovative RATs and operations in different frequency bands. The CR technologies would enable the mobile user "roam freely between different spectrums and choose preferable radio bearer according to cost and QoS", thus resulting in "Always Best Connected" paradigm (Damljanović 2010: 9). However, the QoS concept in the mobile environment is not a static concept and thus its adequacy must be examined thoroughly "as a function of place, time, and social setting (e.g. commuting, shopping, or in need of medical assistance)" (Mitola 2009: 626).

With the world being increasingly challenged by natural disasters and emergency situations, one of the greatest beneficiaries of CR/SDR will be military, police and other governmental services (Damljanović 2010: 9). In situations where particular spectrum is overcrowded due to e.g., disaster-provoked escalation in the number of calling parties, mobile devices operating in one frequency band could change the RAT and have access to other parts of spectrum. A new CR/SDR based standard could bring end to the currently existing fragmentation in emergency communications in Europe, where some countries adopted TETRA $^{5}$, while other - did not.

For the manufacturers, CR should lower the production costs due to the shift from hardware-based rigid design to flexible "software-can-do-all" architecture (Collins 2010; McHale 2010). The volume of terminal and infrastructure equipment will result in additional cost reduction opportunities (European Commission 2009c: 21), diving the price of consumerlevel devices towards the market acceptance threshold. While telecommunications equipment manufacturers have since long been producing firmware upgradeable network and consumer devices, to date, $\mathrm{CR} / \mathrm{SDR}$ remains a niche application, which means that manufacturers don't have incentives to invest into developing the technology. Besides, the cognitive features are likely to create higher entry barriers for manufacturing CR compared to conventional radioand telephony- equipment, as the new technology is more IP intensive (McHale 2010). This can lead to a chicken and egg dilemma - technology vendors will wait for large operators to announce the support for the technology to realize that there is a sufficient volume potential (Tardy, Grøndalen 2010: 107), while the operators, on the other hand, wouldn't support the technology, unless it is standardized and embraced by the manufacturers (European Commission 2009c: 21), and unless they have confidence that consumers would accept the price of the devices.

Terrestrial Trunked Radio (formerly known as Trans-European Trunked Radio) is a professional mobile radio. TETRA was specifically designed for use by government agencies, emergency services, (police forces, fire departments, ambulance) for public safety networks, and the military. 
A common incentive for vendors and operators in supporting CR could be the fact that CR helps shifting operation-defining features of technology from hardware to software, which implies faster sequences of updates and improvement of operating behavior of the equipment (and the services it supports), as well as reduces the equipment implementation costs (European Commission 2009c: 21).

Another interesting driver for CR/SDR business development may arise as a spin off from the constant growth of cellular networks, in which the push for increasingly dense deployment of bases stations led to the emergence of "femtocells". Femtocells are tiny and very low power access points placed directly inside the user premises - homes or office - and providing the users with voice and broadband data connectivity through their mobile phones or wireless Internet dongles (Saunders 2009). Essentially an extension of their mother-networks, femtocells do not need to have CR/SDR capabilities. However, implementing CR/SDR features in femtocell radios would clearly help promoting their wider and more ubiquitous self-deployment through enabling them to handle autonomously the interference situation (CR-part) and providing for seamless transition of radio access technologies (SDR-part).

When analysing all of the above gains for different stakeholders, it would appear that the alternative (i.e. those not having sufficiently large stake in existing networks and technologies) service providers and manufacturers are the two groups that should be most interested in "disruptive" opportunities offered by cognitive radio. For these two groups the cognitive technology and associated (anticipated) regulatory flexibility should act as both the catalyst for technological and business development as well as door-opener to access the spectrum markets which were traditionally characterized as having stringent entry barriers for new players.

However, also traditional players and incumbent operators can achieve significant benefits by embracing CR/SDR technologies, such as evidenced by examples of manufacturing gains as well as new capabilities achievable for emergency network operators as well as traditional cellular network operators.

\subsection{The barriers/challenges to $\mathrm{CR} / \mathrm{SDR}$ adoption}

The concepts of CR/SDR imply certain architectural functionalities, two of which are that of flexible spectrum management and reconfigurability of devices and networks. Selforganization and decentralized control could necessitate the introduction of (different type of) central controlling entities (E2R II 2007: 26; Delaere, Ballon 2008: 7). Ideally, controlling mechanisms should be capable to (Marcus et al. 2005: 5-7; E2R II 2007: 26):

- Define the rules for interacting with competitors, acquiring spectrum, getting access to users etc.

- Ensure that the transaction or administrative costs for spectrum users are as low as possible.

- Provide clear information to prospective spectrum users on "which frequencies are available, what they can be used for, who is currently using them and what needs to be done in order to obtain rights of use" (Marcus et al. 2005: 5). 
- Ensure that frequencies are assigned to those who, in economic terms, can use them most efficiently.

- Prevent users withholding spectrum from trading for speculative reasons or other strategic motives.

- Ensure that sufficient radio spectrum is available for emergency services, distress calls, military users and other institutions that serve the public interest.

If the aforementioned requirements can be fulfilled, mobile communications customers would be granted always-best connectivity for optimally serving equipment and users, in terms of QoS and cost, and seamless mobility for rendering the users agnostic of the heterogeneity of the underlying infrastructure, while ensuring the consistency of application provision in the overall service area (WG3 of ETSI RRS quoted in European Commission 2009b; Mueck et al. 2010: 4). These "mobility and heterogeneity" features imply, among other, moving away from the traditional individual rights of use of spectrum where a license per operator is required to the so-called general authorization scheme with license-exempt or light-licensing regimes (Tardy, Grøndalen 2010: 109).

If no license is required, the equipment will solely have to comply with a pre-defined set of regulatory conditions. In the case of light licensing regime, the users of spectrum are to identify themselves and comply with the set of regulatory conditions (Tardy, Grøndalen 2010: 109). While these changes may be beneficial to new entrant service providers and equipment manufacturers, the drawback with the license-exempt usage for regulators and incumbent service providers is that the more users, the more interference (Tardy, Grøndalen 2010: 109). Therefore it is of paramount importance to construct the regulatory conditions for unlicensed use of cognitive radio so that they provide convincing insurances to regulators and incumbent service providers that the feared explosion of interference would not happen.

In the CR paradigm, it can be very difficult to monitor spectrum for interference (Damljanović 2010: 7) because sharing of spectrum by cognitive radios would make it difficult, if not impossible, to detect excessive sources of interference (Damljanović 2010: 7). Besides, the corresponding monitoring infrastructure would require sizable investment. This, in turn, may prevent the service provider from ensuring previously agreed QoS (Tardy, Grøndalen 2010: 105). Moreover, other than creating excess interference to other (incumbent) users, the CR pose additional danger in that their random behavior in competing for opportunistic spectrum access could lead to severe and hardly predictable interference between two or more CR networks or their terminals operated in the same area and frequency band(s). Such interference issues will require careful consideration and may call for prohibitively complex interference management scenarios, that only recently started to be addressed (Akyildiz et al. 2008).

On the other hand, doing nothing and prohibiting cognitive radio is also not a viable regulatory option since regulators anyway always have to balance with new appearing sources and risks of interference (Damljanović 2010: 7). In that regard it could be noted that the existing R\&TTE Directive is based on declaration of conformity and neither includes type approval nor registration of the equipment nor equipment identifier (Mueck et al. 2010:2) for certain conditions and certain classes of equipment. This means that the regulators have previously opened up the opportunities for industry self-regulation and therefore reverting the trend 
would be now hardly possible. Moreover, the CR/SDR paradigm allows taking this concept one step further - from industry self-regulation to "device self-regulation", thus representing the next evolutionary step in the direction of gradual liberalization of wireless markets.

Regulatory steps alone will not bring about the expected change in technological regime. As an evidence to that is the case of the United States, where the FCC formally announced its intention to open TV-band "white spaces" for unlicensed use already in 2002. Almost a decade later, the FCC hasn't approved a single radio device to use the TV bands, so complicated is the regulatory task of determining how TV stations and low-power radios can share frequencies (Hazlett 2010: 1) and overcoming the persistent campaigning by the TV broadcasters' lobby.

This situation suggests that policymakers' encouragement of investment and innovation must be supported by viable business models driving the deployment of CR/SDR. What exactly these business models are, however, is still unclear (European Commission 2009c: 3).

\section{Discussion and conclusions}

Having reviewed drivers and barriers to establishing a new paradigm of technology and services based on CR/SDR, several distinct business development scenarios can be identified. The available opportunistic spectrum capacity (such as the one provided by TVWS) could be utilized by CR/SDR devices for all four deployment scenarios listed in Table. It appears from the reported analysis that the availability of TVWS is an important factor is deciding on viability of a business case for CR/SDR systems. With the mandatory switch-over from analogue to digital terrestrial TV broadcast ${ }^{6}$, TVWS can provide spectrum resources for a number of user services.

The most complicated and therefore the least likely, in our opinion, case is that of market mechanism (see Table), as such a scheme would require instituting a third-party agency to control transactions within the pool of different RAT owners (service/infrastructure providers) and end users, taking care of billing, QoS, and other contractual obligations between the "supplier" and "consumer" of the resource - the spectrum and the associated RAT. In a way, this agency would represent a new breed of clearinghouse, similar to ones introduced back in the 1970s to take care of clearing roaming charges between different mobile operators. However, the complexity of the job would be much higher, and would require elaborate regulatory system to support the "self-optimization" of the market. The only condition under which such scheme would be acceptable for user, in our view, would be through offering the user a carte-blanche/flat-rate wireless broadband (or voice and broadband) service.

A more likely scenario is that based on the growing presence of "converged" CR-capable personal devices. The functional convergence on the level of personal devices combined with CR/SDR will accelerate deployment of (mobile) Internet services, some of which would come in direct competition with services provided by today's mobile operators on their $3 \mathrm{G}$ and (soon) $4 \mathrm{G}$ networks. For example, users of $3 \mathrm{G}$ and $4 \mathrm{G}$ networks may have access to mobile broadband or VoIP services using the spectrum of TVWS and/or public Wi-Fi hotspots (WLAN). While

6 In the EU countries the switchover must be completed by 2012 at the latest, although a few countries have voluntarily chosen even earlier dates. 
the "cellular + WLAN" scenario has been offered by mobile operators for already a decade, the scheme lacks ubiquity/mobility the cellular users are used to. "Cellular + TVWS", on the other hand, can provide the expected ubiquity in coverage. This scenario would resemble the one of the rollout of GSM 1800 in Europe, when new operators were rolling out GSM 1800 services in competition to the incumbents owning the legacy band of GSM 900. As new networks were built in metropolitan areas first, users were offered lower calling tariffs in these areas, and had to pay higher rates when "roaming" on the legacy 900 band of incumbents in areas where there was no GSM 1800 network available.

The third and fourth scenarios can be played out around the concept of Future Digital Home. On the one hand, with the analogue-to-digital switchover in terrestrial TV broadcast to be completed by 2012, for many people owning a DVB-H enabled phone could be a more attractive alternative to buying set-top boxes for old TVs or buying new digital TVs. User's handheld device may become a multi-mode radio access point, also capable of delivering TV broadcast signal to TV sets not capable of DVB reception. On the other hand, due to the rise of prominence of the home entertainment and VoIP systems, CR/SDR could open the door of opportunity for re-conquering the residential telecommunications market to fixed telephony and (wired) Internet operators. CR/SDR enabled user devices could network between one another, also catering for user's access to the Internet.

For any of the scenarios to be implemented, however, technology standardization must be carried out on the international/global level. In the wireless world, sustainable business models, even at local level, increasingly require global standardized solutions. This tenet may be illustrated by juxtaposing the overwhelming successes of such technological standards as GSM and IEEE 802.11 families to failures of such technology standards as WAPI, WiBro and WIPI. Albeit of different origins (the two former established first by ETSI as regional European standard, and by IEEE SC as industrial standard, respectively; the three latter - by Chinese and Korean governmental and industrial collaborative efforts), the openness of the two former standards along with the clear associated policies for their deployment (the EU Directive and industry cooperation within GSM MoU for GSM, and the transparent globally harmonized unlicensed spectrum access rules for IEEE 802.11) have created a favorable climate in which these standards have developed to the globally ubiquitous technologies of today. The latter three, although successfully developed, without the support of international vendors, policy makers, and standardization community, where brought to halt to a larger or lesser extent (Kwak et al. 2011).

At the backdrop of having harmonized mobile telecom services market in Europe, the regulatory environment, has been changing ever since the GSM. The introduction of a new EU telecommunications regulatory framework in 2002 has paved the way for "technology neutral" regulation, meaning that the European regulators were forced to abolish the practice of imposing the specific technology standards (such as GSM, UMTS) in their regulations. Instead, technology neutral network licences had to be awarded. This led to certain market confusion, when advancement of next generations of wireless technologies was promoted to the consumers under the same tag of " $4 \mathrm{G}$ " by different industry consortia. So, Long Term Evolution (LTE) the next generation of GSM/UMTS family standards was promoted by the 3GPP consortia, and WiMAX, an IEEE 802.16 standard, promoted by WiMAX Forum. Since 
none of the two standards was imposed by the European regulators, the operators had a free choice. However, even though WiMAX was standardized before LTE and WiMAX compatible equipment came first on the market, the incumbent GSM/UMTS operators were reluctant to undergo the technological shift, preferring to wait for the arrival of LTE. As a result, despite being given the free playing ground, WiMAX did not find wide support among the large incumbents. Today WiMAX may be mostly seen across Europe just as a marginal service offering by new telecommunications operators. This suggests that technology neutrality could be a double edge sword. The CR/SDR technology with its multi-RAT capabilities could be indeed offering yet another opportunity for smoothing the technological battles by essentially giving the freedom of technological trials with minimal investment risk.

The same examples let us to finally postulate that some equally clear, fair and transparent policies should be set as regards spectrum access for CR/SDR technologies, along the suggestions indicated in this paper (see Table). Such sound and transparent policies should be ideally complemented by some associated incentives to jump-start the development of these novel technologies in current murky economic times and fuzzy standards-competition situation. Having those policies and incentives would benefit the CR/SDR technologies and through that - many involved stakeholders and end-users at large. The detail of those policies however requires further studies and will be addressed in further works.

\section{Acknowledgment}

This work was supported by the research grant (No. COST-1/2011) from the Research Council of Lithuania and by the COST Action IC0905 TERRA, www.cost-terra.org.

\section{References}

Akyildiz, I. F.; Lee, W. Y.; Vuran, M. C.; Mohanty, S. 2008. A survey on spectrum management in cognitive radio networks, IEEE Communications Magazine 46: 40-48. http://dx.doi.org/10.1109/MCOM.2008.4481339

Brown, T. X.; Sicker, D. C. 2007. Can cognitive radio support broadband wireless access?, in The 2nd IEEE International Symposium on New Frontiers in Dynamic Spectrum Access Networks (DySPAN'07). Dublin, Ireland: IEEE, 123-132.

Burinskienè, M. 2009. New methodology for sustainable development towards sustainable transportation system, Technological and Economic Development of Economy 15(1): 5-9. http://dx.doi.org/10.3846/1392-8619.2009.15.5-9

Collins, L. 2010. 'Whisky and soda' solution to software-defined radio architecture, in I\&T Engineering and Technology Magazine. The Institution of Engineering and Technology. Published June 21. Available from Internet: http://eandt.theiet.org/news/2010/june/cognov.cfm

Damljanović, Z. 2010. Mobility management strategies in heterogeneous cognitive radio networks, Journal of Network and Systems Management 18(1): 4-22. http://dx.doi.org/10.1007/s10922-009-9146-0

Delaere, S.; Ballon, P. 2007. Model implications of a cognitive pilot channel as enabler of flexible spectrum management, in 20th Bled eConference eMergence: Merging and Emerging Technologies, Processes, and Institutions. Bled, Slovenia.

Delaere, S.; Ballon, P. 2008. Multi-level standardization and business models for cognitive radio: the case of the cognitive pilot channel, in The 3rd IEEE Symposium on New Frontiers in Dynamic Spectrum Access Networks (DySPAN’08). Chicago, IL: IEEE. 
E2R II. 2007. The E2R II Flexible Spectrum Management (FSM) - Technical, Business \& Regulatory Perspectives. IST-2003-507995 Project Report. Brussels. Available from Internet: https://ict-e3.eu/project/ white_papers/e2r/5.E2RII_FSM_White_Paper.pdf

European Commission. 2009a. Future Networks. The Way Ahead! Brussels. Available from Internet: http://cordis.europa.eu/fp7/ict/future-networks/publications/the-way-ahead.pdf

European Commission. 2009b. ICT Work Programme 2009-2010 Objective ICT-2009.1.1: The Network of the Future [online]. CORDIS. Brussels. Available from Internet: http://cordis.europa.eu/fp7/ict/ future-networks/home_en.html

European Commission. 2009c. Radio Spectrum Policy Group Report On “Cognitive Technologies". Final Draft. Brussels. Available from Internet: http://rspg.groups.eu.int/_documents/documents/meeting/ rspg20/rspg09_299.pdf

Federal Communications Commission. 2010. Spectrum Analysis: Options for Broadcast Spectrum: FCC. Washington, D.C. Available from Internet: http://transition.fcc.gov/Daily_Releases/Daily_Business/2010/db1130/FCC-10-196A1.pdf

Fomin, V. V. 2001a. Innovation, standardization, and sustainable development of cellular mobile communications on three continents, in Dittrich, K.; Egyedi, T. M. (Eds.). The 6th EURAS Workshop on Standards, Compatibility and Infrastructure Development. Delft, The Netherlands: Delft University of Technology, 99-116. http://dx.doi.org/10.1007/s12130-001-1016-3

Fomin, V. V. 2001b. The role of standards in sustainable development of cellular mobile communications, Knowledge, Technology and Policy 14: 55-70. http://dx.doi.org/10.4018/978-1-878289-70-4.ch014

Fomin, V. V.; Lyytinen, K. 2000. How to distribute a cake before cutting it into pieces: Alice in Wonderland or radio engineers' gang in the Nordic Countries?, in Jakobs, K. (Ed.). Information Technology Standards and Standardization: A Global Perspective. Hershey: Idea Group Publishing, 222-239.

Hazlett, T. 2010. Putting Economics Above Ideology [online]. Barron's. Available from Internet: www.barrons.com

Huang, S.; Liu, X.; Ding, Z. 2008. Opportunistic spectrum access in cognitive radio networksed, in The 27th Conference on Computer Communications (INFOCOM'08). Phoenix, AZ: IEEE, 1427-1435.

Kloch, C.; Bilstrup, B.; Vesterholt, C. K.; Pedersen, T. P. 2009. Roadmap for Software Defined Radio - A Technology, Market and Regulation Perspective. Copenhagen. Available from Internet: http://www.teknologisk.dk/24764,3

Kwak, J.; Lee, H.; Fomin, V. V. 2011. The governmental coordination of conflicting interests in standardisation: case studies of indigenous ICT standards in China and South Korea, Technology Analysis and Strategic Management 23(7): 789-806. http://dx.doi.org/10.1080/09537325.2011.592285

Lera, E. 2000. Changing relations between manufacturing and service provision in a more competitive telecom environment, Telecommunications Policy 24: 413-437. http://dx.doi.org/10.1016/S0308-5961(00)00029-X

Marcus, J. S.; Nett, L.; Scanlan, M.; Stumpf, U.; Cave, M.; Pogorel, G. 2005. Towards More Flexible Spectrum Regulation. Study for the Federal Network Agency. Study for the Federal Network Agency. Delft.

McHale, J. 2010. Software-defined radio technology is enhancing communications in military and commercial applications worldwide, Military and Aerospace Electronics. Online magazine. Available from Internet: http://www.militaryaerospace.com/articles/2008/09/software-defined-radio-technology-isenhancing-communications-in-military-and-commercial-applications-worldwide.html

Melnikas, B. 2010. Sustainable development and creation of the knowledge economy: the new theoretical approach, Technological and Economic Development of Economy 16(3): 516-540. http://dx.doi.org/10.3846/tede.2010.32

Mishra, M.; Sahai, A. 2009. How much white space is there?, Tech. Rep. UCB/EECS-2009-3.

Mitola, J. I. 1999. Cognitive radio for flexible mobile multimedia communicationsed, in Mobile Multimedia Communications (MoMuC'99). San Diego, CA: IEEE, 3-10. 
Mitola, J. I. 2000. Cognitive Radio: an Integrated Agent Architecture for Software Defined Radio. Royal Inst. Technol. (KTH). Stockholm.

Mitola, J. I. 2009. Cognitive radio architecture evolution, in Proceedings of the IEEE 97, 626-641.

Mueck, M.; Piipponen, A.; Dimitrakopolous, G.; Tsagkaris, K.; Casadevall, F.; Demestichas, P.; PéRezRomero, J.; Sallent, O.; Baldini, G.; Filin, S.; Harada, H.; Debbah, M.; Haustein, T.; Gebert, J.; Deschamps, B.; Bender, P.; Street, M.; KalliojäRvi, K.; Kandeepan, S.; Lota, J.; Hayar, A. 2010. ETSI reconfigurable radio systems - status and future directions on software defined radio and cognitive radio standards, IEEE Communications Magazine 48: 78-86.

http://dx.doi.org/10.1109/MCOM.2010.5560591

Nekovee, M. 2010. A survey of cognitive radio access to TV white spaces, International Journal of Digital Multimedia Broadcasting. http://dx.doi.org/10.1155/2010/236568

OECD. 1999. Managing National Innovation Systems. Available from Internet: http://www.oecd.org/Lon gAbstract/0,3425,en_2649_34273_1911822_1_1_1_1,00.html

Paetsch, M. 1993. The Evolution of Mobile Communications in the U.S. and Europe: Regulation, Technology, and Markets. London: Artech House.

Sakalauskas, L.; Zavadskas, E. K. 2009. Optimization and intelligent decisions, Technological and Economic Development of Economy 15(2): 189-196. http://dx.doi.org/10.3846/1392-8619.2009.15.189-196

Saunders, S. 2009. Introduction to Femtocells, in Saunders, S.; Carlaw, S.; Giustina, A.; Raj Bhat, R.; Srinivasa Rao, V.; Siegberg, R. (Eds.). Femtocells: Opportunities and Challenges for Business and Technology. John Wiley \& Sons, Ltd, 1-16.

Stankevičius, Ž.; Beconyte, G.; Kalantaite, A. 2010. Automation of update of digital national geo-reference databases, Technological and Economic Development of Economy 16(2): 254-265. http://dx.doi.org/10.3846/tede.2010.16

Stewart, J.; Dorfer, W.; Pitt, L.; Eskedal, T.; Gaarder, K.; Winskel, M.; Evans, D.; Williams, R.; Stimming, C. 2003. Cost and Benefit of Use Scenarios. The Selection Environment for MIMO-enabled Multi-standard Wireless Devices Including Cost Benefit Analysis of Various Convergence Technologies. Edinburgh: The University of Edinburgh.

Stewart, J.; Wang, C. 2010. Final Report on Standards Dynamics in Mobile Broadband. China EU Information Technology Standards Research Partnership. Edinburgh: The University of Edinburgh.

Tardy, I.; Grøndalen, O. 2010. Which regulation for cognitive radio? An operator's perspective, Telektronikk 1: 105-120.

West, J. 2000. Institutional constraints in the initial deployment of cellular telephone service on three continents, in Jakobs, K. (Ed.). Information Technology Standards and Standardization: a Global Perspective. Hershey: Idea Group Publishing, 198-221. http://dx.doi.org/10.4018/978-1-878289-70-4.ch013

Zhao, Q. 2007. Cognitive radio for flexible mobile multimedia communicationsed, in Acoustics, Speech and Signal Processing (ICASSP'07). Honolulu, HI: IEEE, III-605-III-608.

Vladislav V. FOMIN is a professor and head of department of Applied Informatics at Vytautas Magnus University in Kaunas, Lithuania, and a principal research fellow at The School of Business Administration Turība in Riga, Latvia. Fomin's current research interests include studies of development of information and communication technologies (ICT) infrastructure, studies of design and implementation of Information Systems (IS) in organizations, standard making processes in the field of ICT, as well as studies of technology innovation. Vladislav is serving on the editorial board of the International Journal of IT Standards \& Standardization Research (JITSR), is a member of European Academy of Standardization (EURAS) and The Association for Information Systems (AIS). Vladislav has authored or co-authored more than 60 publications on topics related to standards and standardization, innovation, and mobile communications. 
Artūras MEDEIŠIS holds a Ph.D. from Kaunas University of Technology, Lithuania, with thesis in radio spectrum management and engineering. Currently he is Associate Professor at the Telecommunications Engineering Department of Vilnius Gediminas Technical University, Lithuania. He has over 15 years of research and practical experience in the fields of radiocommunications planning and spectrum management. He led several committees and activities in various standardization and policy forums, such as ITU, CEPT, ETSI. Currently he chairs European COST Action IC0905 TERRA that develops regulatory framework for Cognitive Radio. Arturas has authored or co-authored around 30 publications on a variety of topics in wireless communications, including book chapters and parts of ITU handbooks.

Daiva VITKUTE்-ADŽGAUSKIENE் is the Dean of the Faculty of Informatics at Vytautas Magnus University, Kaunas, Lithuania. She studied Applied mathematics at Kaunas Technology university, got her Ph.D. degree in informatics from Vytautas Magnus University and EMBA from Baltic Management institute. She has 20 years of teaching experience in informatics, and has also worked for more than 10 years with a mobile operator in Lithuania leading the development of advanced mobile services and solutions. She participated in different international projects, including JEP-4298 (Tempus), RAPIDITY (Phare Multi-Country Programme in Distance Education), ALIPRO (FP6), OpenScout (eContentplus) and others. Her main research interests are: system simulation and control; innovations in mobile solution development; computerized text mining and semantic analysis. Her publication list includes over 30 papers and conference contributions. 